\title{
Eksperimen Optimasi Kekerasan Paduan Kuningan dengan Metode Desain Faktorial $3^{3}$
}

\author{
Novira Dwi Rahma', Gunawan Madyono Putro ${ }^{1}$, S.Sadi $^{1}$, Muhammad Shodiq Abdul Khannan ${ }^{1}$ \\ ${ }^{1}$ Jurusan Teknik Industri Fakultas Teknik Industri \\ Universitas Pembangunan Nasional Veteran Yogyakarta \\ Jl. Babarsari No. 2 Tambakbayan, Yogykarta 55281 \\ email :shodiq@upnyk.ac.id \\ doi: https://doi.org/10.31315/opsi.v12i2.3150
}

Received: $16^{\text {th }}$ October 2019; Revised: $20^{\text {th }}$ November 2019; Accepted: $30^{\text {th }}$ December 2019;

Available online: 31 $1^{\text {st }}$ December 2019; Published regularly: December 2019

\begin{abstract}
Brass material is widely used by SME industries in Indonesia including the gamelan industry, the pottery industry, and the handicraft industry. This research aims to improve the quality of brass material which is a combination of copper and nickel material. The ability of the manufacturing industry in Indonesia in processing mining raw materials with good quality is still low. There has not been a specific effort to improve quality through research and development. The long-term goal of this research is to build excellence in the material field in Indonesian industries. This advantage is very important for industries in Indonesia to compete globally.

The method used is a 3 variable factorial design (temperature, temper time, cooling media) with each of 3 levels (33) to determine the most influential factors and improve product quality so that the highest level of product hardness. From the results of data processing obtained from the three factors that have a significant effect and settings that provide the greatest level of violence.
\end{abstract}

Keywords: Experimental design, Quality; Brass; Full factorial

\begin{abstract}
ABSTRAK
Bahan kuningan banyak digunakan oleh industri-industri UKM di Indonesia di antaranya adalah industri gamelan, industri gerabah, dan industri kerajinan. Penelitian ini bertujuan untuk meningkatkan kualitas material kuningan yang merupakan perpaduan bahan tambang tembaga dan nickel. Kemampuan industri manufaktur di Indonesia dalam mengolah bahan baku tambang dengan kualitas bagus masih rendah. Belum ada upaya secara khusus untuk meningkatkan kualitas melalui penelitian dan pengembangan. Tujuan Jangka panjang dari penelitian ini adalah membangun keunggulan di bidang material di industri-industri Indonesia. Keunggulan ini sangat penting dimiliki industri-industri di Indonesia agar bisa bersaing secara global.

Metode yang digunakan adalah desain faktorial 3 variabel (temperatur, temper time, media pendinginan) dengan masing-masing sebanyak 3 level $\left(3^{3}\right)$ untuk mengetahui faktor yang paling berpengaruh dan meningkatkan kualitas produk sehingga tingkat kekerasan produk paling tinggi. Dari hasil pengolahan data didapatkan dari ketiga faktor berpengaruh secara signifikan dan setting yang memberikan tingkat kekerasan yang paling besar.
\end{abstract}

Kata Kunci: Desain eksperimen; Kualitas; Kuningan; Ful faktorial

\section{PENDAHULUAN}

Bahan kuningan banyak digunakan oleh industri-industri UKM di Indonesia di antaranya adalah industri gamelan, industri gerabah, dan industri kerajinan. Penelitian ini bertujuan untuk meningkatkan kualitas material kuningan yang merupakan perpaduan bahan tambang tembaga dan nickel. Kemampuan industri manufaktur di Indonesia dalam mengolah bahan baku tambang dengan kualitas bagus masih rendah. Belum ada upaya secara khusus untuk meningkatkan kualitas melalui penelitian dan pengembangan.
Tujuan Jangka panjang dari penelitian ini adalah membangun keunggulan di bidang material di industri-industri Indonesia. Keunggulan ini sangat penting dimiliki industri-industri di Indonesia agar bisa bersaing secara global.

Dalam rangka mewujudkan kualitas tersebut UKM perlu melakukan peningkatan kualitas dari bahan baku dan proses produksinya. Metode yang bisa digunakan adalah metode desain eksperimen full factorial Kualitas, konsep kualitas sering dianggap sebagai ukuran relatif kebaikan atau nilai dari suatu produk atau jasa. Kualitas memiliki 
banyak ragam definisi menurut para ahli, hal ini disebabkan karena adanya perbedaan perspektif atau pandangan yang digunakan. Menurut Nasution (2001) terdapat 5 pakar utama dalam manejemen mutu terpadu (TQM) yang memiliki pendapat yang berbeda dalam mendefinisikan kualitas produk, walaupun memiliki maksud yang sama. (a) Menurut Juran, kualitas produk adalah kecocokan penggunaan produk (fitness for use) untuk memenuhi kebutuhan dan kepuasan pelanggan.

Kecocokan penggunaan itu didasarkan pada 5 ciri utama berikut: a. Teknologi, yaitu kekuatan atau daya tahan. b. Psikologis, yaitu citra rasa atau stastus. c. Waktu, yaitu kehandalan. d. Kontraktual, yaitu adanya jaminan. e. Etika, yaitu sopan santun, ramah dan jujur. Selain itu, kecocokan penggunaan suatu produk memiliki dua aspek utama, yaitu ciri-ciri produknya memenuhi tuntutan pelanggan dan tidak memiliki kelemahan sebagai berikut : a. Ciri-ciri produk yang memenuhi permintaan pelanggan Kualitas yang lebih tinggi memungkinkan perusahaan meningkatkan keupasan pelanggan, membuat produk laku terjual, dapat bersaing dengan pesaing, meningkatkan pangsa pasar dan volume penjualan, serta dapat dijual dengan harga yang lebih tinggi. b. Bebas dari kekuranganKualitas yang tinggi menyebabkan perusahaan dapat mengurangi tingkat kesalahan, megurangi pekerjaan kembali dan pemborosan, mengurangi pembayaran biaya garansi, mengurangi ketidakpuasan pelanggan, mengurangi inspeksi dan pengujian hasil (yield) dan kapasitas, dan memperbaiki kinerja penyampaian produk atau jasa. (b) Menurut Crosby (1979), kualitas adalah performance to requirement, yaitu sesuai dengan yang diisyaratkan atau distandarkan. Suatu produk memiliki kualitas apabila sesuai dengan standar kualitas yang telah ditentukan. Standar kualitas meliputi bahan baku, proses produksi, dan produk jadi. (c) Menurut Deming (1982), kualitas adalah kesesuaian dengan kebutuhan pasar atau konsumen. Perusahaan harus benarbenar dapat memahami apa yang dibutuhkan konsumen atas suatu produk yang akan dihasilkan. (d) Menurut Feigenbaum (1986), kualitas adalah kepuasan pelanggan sepenuhnya. Suatu produk dikatakan berkualitas apabila dapat memberikan kepuasan sepenuhnya kepada konsumen, yaitu sesuai dengan apa yang diharapakan konsumen atas suatu produk. (e) Menurut Garvin (1988), kualitas merupakan suatu kondisi dinamis yang berhubungan dengan produk, manusia atau tenaga kerja, proses dan tugas, serta lingkungan yang memenuhi harapan pelanggan atau konsumen.

Meskipun tidak ada definisi mengenai kualitas yang diterima secara universal, yaitu dalam elemen-elemen sebagai berikut: kualitas meliputi usaha memenuhi atau melebihi harapan pelanggan, kualitas mencakup produk, jasa manusia, proses, dan lingkungan, kualitas merupakan kondisi yang selalu berubah. Berdasarkan elemen-elemen tersebut, menurut Goetsch dan Davis (1994) seperti yang dikutip oleh Tjiptono dan Diana (2001) membuat definisi mengenai kualitas yang lebih luas cakupannya. Definisi tersebut adalah "Kualitas merupakan suatu kondisi dinamis yang berhubungan dengan produk atau jasa, manusia, proses, dan lingkungan yang memenuhi atau melebihi harapan."

Desain Eksperimen, desain eksperimen adalah suatu rancangan percobaan lengkap dengan langkah-langkah yang akan dilakukan guna menghasilkan informasi yang berhubungan atau diperlukan untuk persoalan yang sedang diteliti. Dengan kata lain, desain eksperimen merupakan langkah-langkah lengkap yang perlu diambil sebelum eksperimen dilakukan agar data yang diperlukan dapat diperoleh, sehingga analisis dan kesimpulan yang objektif untuk persoalan yang sedang dibahas dapat dicapai (Sudjana, 1991).

\section{METODE}

Penelitian dilakukan di laboratorium Proses Manufaktur Universitas Pembangunan Nasional Veteran Yogyakarta dengan bahan ingot kuningan. Metode pengumpulan data untuk mendapatkan informasi dalam menyusun laporan ini data yang diperoleh berupa: faktorfaktor kontrol yang ditetapkan antara lain : temperatur (A), waktu pendinginan (B), Media pendingin (C), Level faktor yang didigunakan adalah 3 level. Variabel respon yang digunakan yaitu pengujian kekerasan logam (Brinell test) terhadap hasil cor kuningan. Tahap yang dilakukan untuk menyelesaikan penelitian ini adalah sebagai berikut menggunakan metode full faktorial $3^{3}$. 
Tabel 1. Penentuan Jumlah Level dan Nilai Level 3 kali replikasi.

\begin{tabular}{lccc}
\hline Faktor Faktor & Level 1 & Level 2 & Level 3 \\
\hline Temperatur & 300 & 400 & 500 \\
(A) & & & \\
Waktu & 45 & 60 & 75 \\
pendinginan & menit & menit & menit \\
(B) & & & \\
Quench atau & oli SAE & oli SAE & oli SAE \\
media & 10 & 20 & 40 \\
pendinginan & & & \\
(C) & & & \\
\hline
\end{tabular}

Variabel respon yang digunakan yaitu pengujian kekerasan logam (Brinell test) terhadap hasil cor kuningan. Tahap yang dilakukan untuk menyelesaikan penelitian ini adalah sebagai berikut menggunakan metode full faktorial $3^{3}$. (a) Mencari efek utama faktor dan interaksi yang berpengaruh terhadap respon. Untuk mengetahui efek-efek yang berpengaruh terhadap respon dapat dilakukan dengan membuat Plot Probabilitas Normal untuk semua efek yang ada. Penyimpangan yang mencolok dari garis normal menunjukkan bahwa efek tersebut berpengaruh terhadap respon. (b) Melakukan pengujian statistik. Setelah mengetahui efek-efek yang berpengaruh besar terhadap respon maka dilanjutkan dengan membuat Anova (Analysis of Variance), untuk mendapatkan efek faktor dan efek interaksi yang signifikan. (c) Menyusun model regresi. Membuat model regresi berdasarkan efek faktor dan interaksi yang signifikan. (d) Menguji residual. Pengujian residul harus memenuhi 3 asumsi yaitu: Identik, Independent dan berdistribusi normal. (e) Menentukan kombinasi faktor yang optimal. Penentuan level-level faktor yang memaksimalkan kekuatan hasil cetakan klinthing maka perlu dibuat plot efek utama dan plot efek interaksi antar faktor. Plot interaksi yang akan dibuat hanya untuk efek interaksi yang berpengaruh secara signifikan. Kombinasi faktor yang optimal didapatkan dengan cara mengkombinasikan plot efek utama dan plot efek interaksi antar faktor.

Pengumpulan Data, pada penelitian ini, data yang dibutuhkan adalah data rencana eksperimen masing-masing kondisi perlakuan dan data kekerasan masing-masing kondisi perlakuan. Pengolahan data, Mencari efek utama faktor dan interaksi yang berpengaruh terhadap respon, mengetahui efek-efek yang berpengaruh terhadap respon dapat dilakukan dengan membuat Plot Probabilitas Normal untuk semua efek yang ada. Penyimpangan yang mencolok dari garis normal menunjukkan bahwa efek tersebut berpengaruh terhadap respon. Hasil plot probabilitas normal yang telah dibuat dapat dilihat pada Gambar 1.

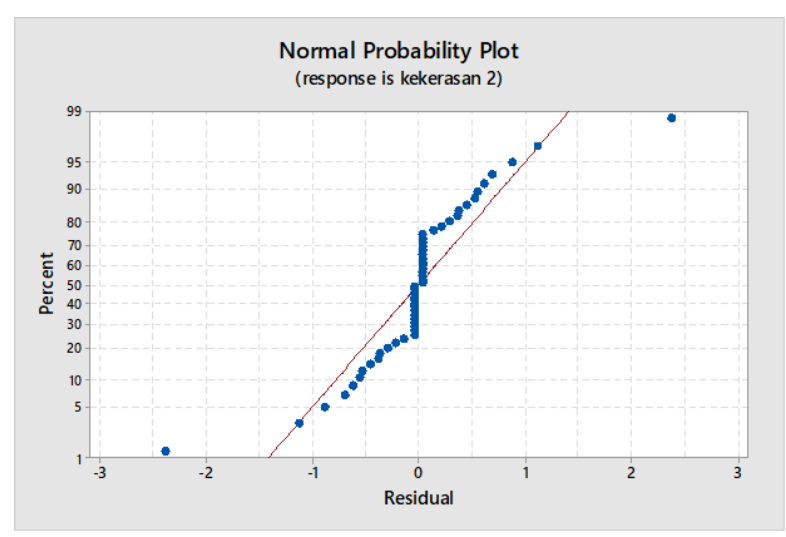

Gambar 1. Plot Probabilitas Normal

Melakukan pengujian statistic, setelah mengetahui efek-efek yang berpengaruh besar terhadap respon maka dilanjutkan dengan membuat Anova (Analysis of Variance), untuk mendapatkan efek faktor dan efek interaksi yang signifikan. Hasil perhitungan anova yang telah dilakukan dapat dilihat pada Tabel 2.

Tabel 2. Perhitungan anova

$\begin{array}{lrrrrr}\text { Analysis of Variance } & & & & \\ \text { Source } & \text { DF } & \text { Adj SS } & \text { Adj MS } & \text { F-Value } & \text { P-Value } \\ \text { Model } & 27 & 253,563 & 9,3912 & 12,45 & 0,000 \\ \text { Blocks } & 1 & 0,063 & 0,0631 & 0,08 & 0,775 \\ \text { | Linear } & 6 & 100,689 & 16,7814 & 22,25 & 0,000 \\ \text { A } & 2 & 10,202 & 5,1010 & 6,76 & 0,004 \\ \text { B } & 2 & 54,809 & 27,4046 & 36,34 & 0,000 \\ \text { C } & 2 & 35,677 & 17,8387 & 23,65 & 0,000 \\ \text { 2-Way Interactions } & 12 & 128,639 & 10,7200 & 14,21 & 0,000 \\ \text { A*B } & 4 & 104,065 & 26,0162 & 34,50 & 0,000 \\ \text { A*C } & 4 & 15,986 & 3,9964 & 5,30 & 0,003 \\ \text { B*C } & 4 & 8,589 & 2,1473 & 2,85 & 0,044 \\ \text { 3-Way Interactions } & 8 & 24,172 & 3,0215 & 4,01 & 0,003 \\ \text { A*B*C } & 8 & 24,172 & 3,0215 & 4,01 & 0,003 \\ \text { Error } & 26 & 19,608 & 0,7541 & & \\ \text { Total } & 53 & 273,171 & & & \end{array}$

Menyusun model regresi, membuat model regresi berdasarkan efek faktor dan interaksi yang signifikan. Hasil perhitungan regresi yang didapatkan dengan menggunakan software Minitab versi 17 dapat dilihat pada Tabel 3.

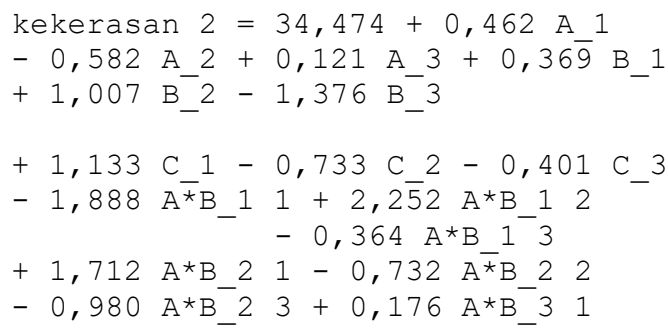




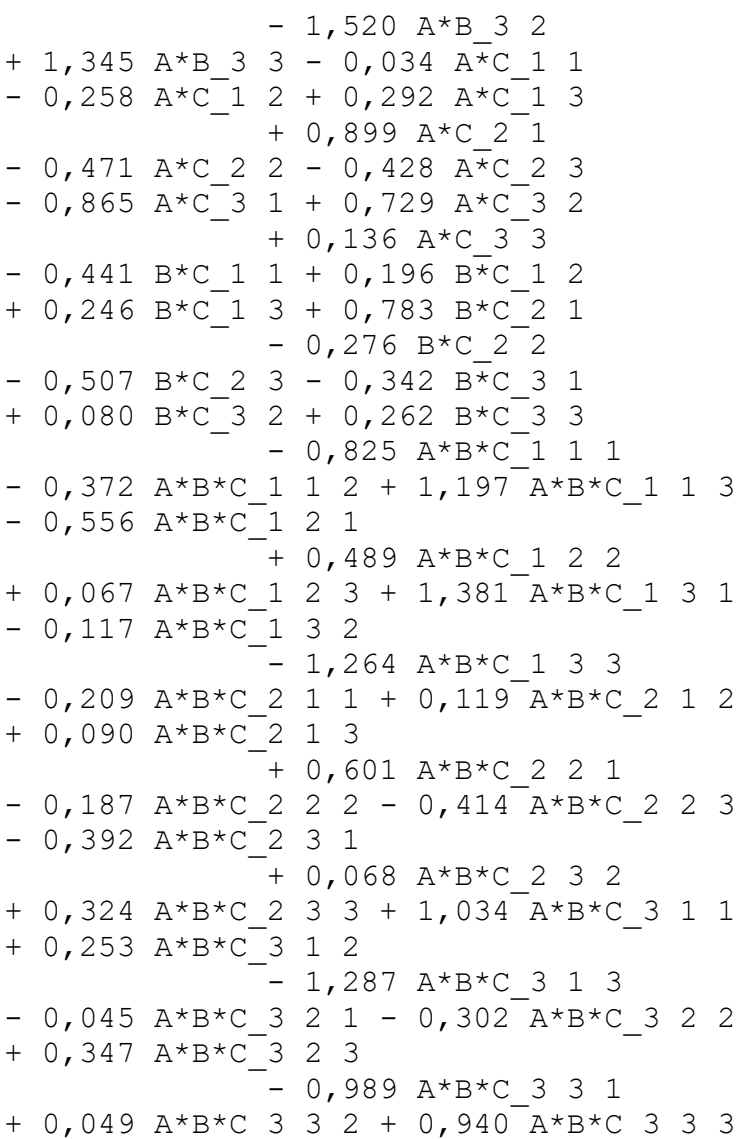

\section{HASIL DAN PEMBAHASAN}

Hasil pengujian residual yang telah dilakukan dapat dilihat pada Gambar 2.

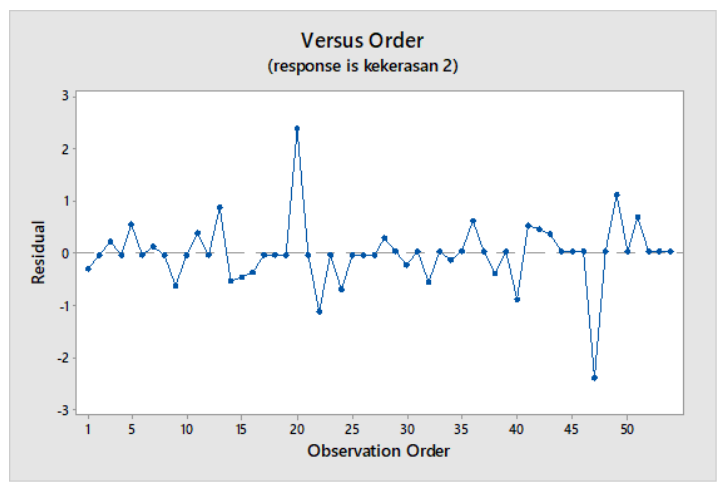

Gambar 2. Residual Versus The Order of Data

Menentukan kombinasi faktor yang optimal, menentukan level-level faktor yang memaksimalkan kekuatan hasil cetakan klinthing maka perlu dibuat plot efek utama dan plot efek interaksi antar faktor. Plot interaksi yang akan dibuat hanya untuk efek interaksi yang berpengaruh secara signifikan. Kombinasi faktor yang optimal didapatkan dengan cara mengkombinasikan plot efek utama dan plot efek interaksi antar faktor. Hasil kombinasi yang optimal dapat dilihat pada Gambar 5, Gambar 6 dan Gambar 7. Dari hasil tabel eksperimen, perlakuan yang memberikan nilai kekerasan bahan yang paling tinggi adalah pada level temperature level 1 , temper time 2 , quench 1 .

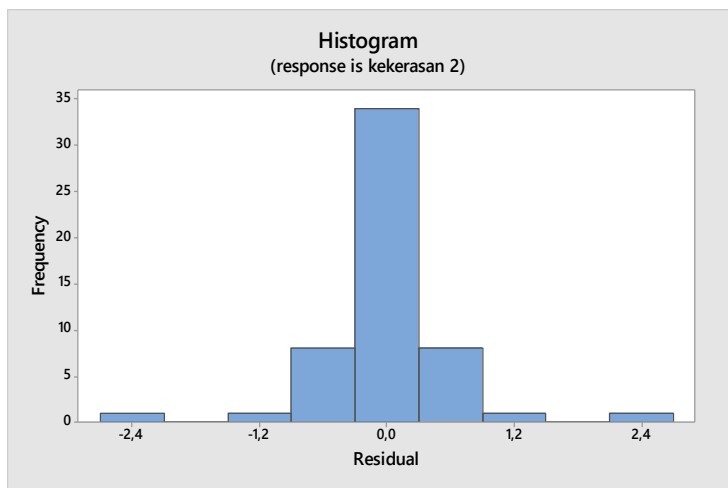

Gambar 3. Histogram residual

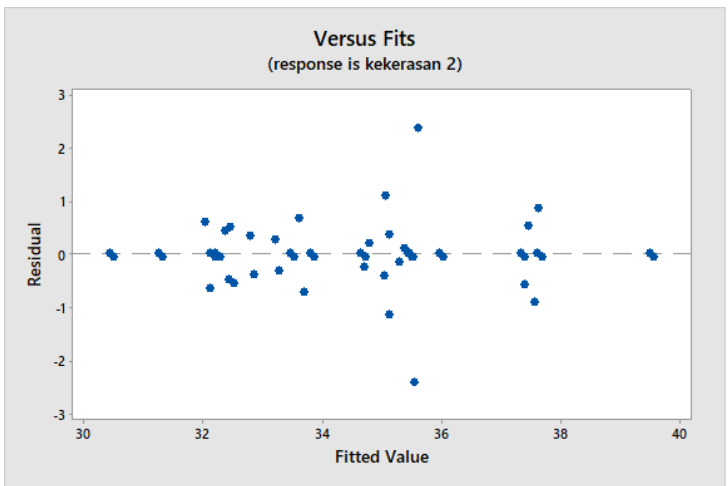

Gambar 4. Heteroskedastisitas residual minitab

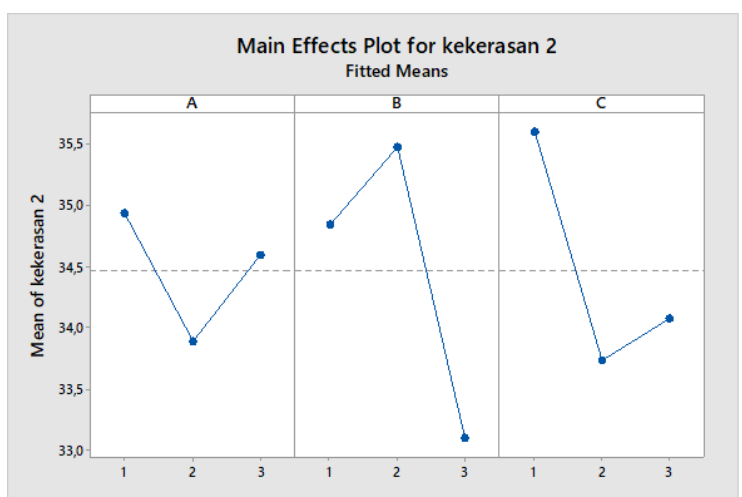

Gambar 6. Efek utama plot kekerasan

Kombinasi setting yang optimal untuk adalah temperature level $1\left(300^{\circ} \mathrm{C}\right)$, waktu pendinginan time 60 menit, dan media pendinginan 1 yaitu oli SAE10 yaitu sebesar 29,5209 HRC. 


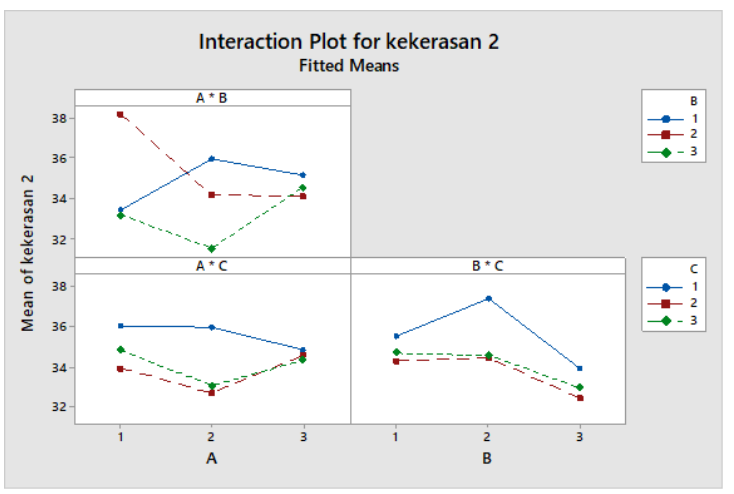

Gambar 7. Efek interaksi plot Kekerasan

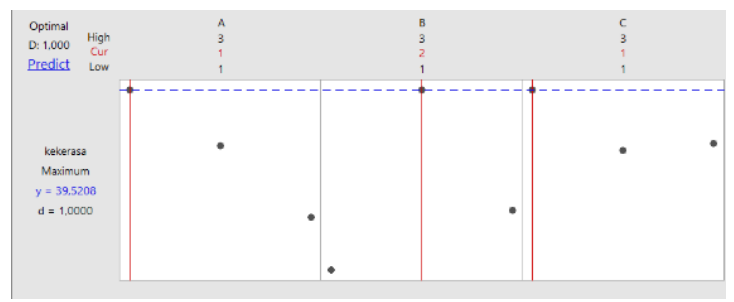

Gambar 8. Plot setting optimal plot Kekerasan

\section{KESIMPULAN}

Berdasarkan pengolahan data analisa hasil penelitian disimpulkan: (a) Faktor-faktor yang berpengaruh secara signifikan terhadap kualitas bahan baku kuningan antara lain adalah: temperature level waktu pendinginan time, dan media pendinginan. (b) Kombinasi setting yang optimal untuk adalah temperature level 1 $\left(300^{\circ} \mathrm{C}\right)$, waktu pendinginan time 60 menit, dan media pendinginan 1 yaitu oli SAE10 yaitu sebesar 29,5209 HRC

\section{DAFTAR PUSTAKA}

Alma, B, (2011), Manajemen Pemasaran dan Pemasaran Jasa, Penerbit Alfabeta, Bandung.

Arifianto, F.S, Saleh, M,A.F dan Anisa, (2013), Identifikasi Faktor Signifikan pada Rancangan Faktorial Fraksional $2^{k-p}$, Jurnal Matematika Statistika, Komputasi Vol, 9 No,2 (Diakses pada tanggal $14 \mathrm{Mei}$ 2018).

Gaspersz, V, (1991), Metode perancangan percobaan, CV,ARMICO, Bandung.

Montgomery, D,C, (2001), Introduction to Statistical Quality Control, 4th Edition, John Wiley \& Sons, Inc., New York.

Montgomery, D,.C, (2005), Supplemental Text Material For Each Chapter of The 6th Edition of Design and Analysis of Experiments, Http://www,wiley,com/ college/Montgomery. 